\title{
Static and Functional Balance in Individuals With COPD: Comparison With Healthy Controls and Differences According to Sex and Disease Severity
}

\author{
Larissa A de Castro MSc, Laís RG Ribeiro MSc, Rafael Mesquita MSc, \\ Débora R de Carvalho MSc, Josiane M Felcar PhD, Myriam F Merli MSc, \\ Karen BP Fernandes PhD, Rubens A da Silva PhD, Denilson C Teixeira PhD, \\ Martijn A Spruit PhD, Fabio Pitta PhD, and Vanessa S Probst PhD
}

\begin{abstract}
BACKGROUND: Studies have shown that individuals with COPD have impaired body balance, probably caused by the disease's multisystemic manifestations plus age-related decline in balance, potentially increasing the risk of falling and its consequences. However, little is known about the profile of individuals with COPD who present balance impairments, especially related to sex and disease severity stages. The aim of this work was to compare static and functional balance between subjects with COPD and healthy controls and to check possible differences according to sex and degrees of disease severity. METHODS: Forty-seven subjects with COPD and 25 healthy controls were included in this study. Their static balance was assessed in one-legged stance using a force platform and functional balance with the Timed Up and Go test. Additionally, participants performed spirometry, the 6-min walk test and isometric quadriceps maximal voluntary contraction assessment. Disease severity was classified according to the Global Initiative for Obstructive Lung Disease stages and BODE (body mass index, air-flow obstruction, dyspnea, and exercise capacity) scores. RESULTS: In comparison with healthy controls, subjects with COPD had worse static (center of pressure displacement area: $9.3 \pm 1.9 \mathrm{~cm}^{2}$ vs $11.6 \pm 4.0 \mathrm{~cm}^{2}$, respectively, $P=.01$ ) and functional balance (Timed Up and Go test: $8.5 \pm 1.3 \mathrm{~s}$ vs $10.3 \pm 1.8 \mathrm{~s}$, respectively, $P<.001$ ). In the COPD group, men performed better in the Timed Up and Go test than women $(9.8 \pm 1.2 \mathrm{~s}$ vs $10.9 \pm 2.2 \mathrm{~s}$, respectively, $P=.03$ ), whereas women presented a better static balance in comparison with men for all parameters related to center of pressure $(P<.005$ for all $)$. Disease severity did not affect any balance results. CONCLUSIONS: Individuals with COPD had worse static and functional balance in comparison with healthy controls. Sex can mediate these results, depending on the type of balance evaluation (force platform or functional test). Balance performance was similar among the groups classified according to disease severity. Key words: COPD; postural balance; accidental falls; symptoms; risk factors; disability evaluation. [Respir Care 2016;61(11):1488-1496. (C) 2016 Daedalus Enterprises]
\end{abstract}

\section{Introduction}

COPD is a major global health problem, since it is the fourth leading cause of death in developed countries ${ }^{1}$ and

Ms de Castro, Ms Ribeiro, Dr Felcar, Ms Merli, Dr Fernandes, Dr da Silva, Dr Teixeira, and Dr Probst are affiliated with the Research Centre in Health Sciences (CPCS), University of Northern Parana (UNOPAR), Londrina, Brazil. Ms de Castro, Mr Mesquita, Ms de Carvalho, Dr Pitta, and Dr Probst are affiliated with the Laboratory of Research in Respi- ratory Physiotherapy (LFIP), Physiotherapy Department, Londrina State University (UEL), Londrina, Brazil. Mr Mesquita and Dr Spruit are affiliated with the Department of Research and Education, CIRO, Center of Expertise for Chronic Organ Failure, Horn, The Netherlands. Mr Mesquita is affiliated with the Department of Respiratory Medicine, Maastricht University Medical Center+ $($ MUMC +$)$, Maastricht, The Netherlands. Dr Teixeira is affiliated with the Centre for Physical Education and Sports, Department of Physical Education, Londrina State University (UEL), Londrina, Brazil. Dr Spruit is affiliated with 
estimated to become the third leading cause in $2030 .^{2}$ Although it has been considered primarily as a pulmonary disease, it is well recognized that people with COPD also suffer from many non-respiratory manifestations, such as muscle dysfunction, systemic inflammation, and malnutrition ${ }^{3}$.

In addition, studies have suggested that individuals with COPD generally have impaired balance. ${ }^{4-6}$ The mechanisms are not completely clear; however, there is a relationship between the disease's multisystemic manifestations and balance deterioration. ${ }^{4-6}$ This deterioration is added to the aging-related decline in balance. ${ }^{7}$ Therefore, it is reasonable to infer that most individuals with COPD are doubly affected (ie, by both the aging process and disease progression).

The main consequence of poor balance is the increased risk of falling. ${ }^{8-11}$ It has particular importance for patients with COPD, since they also present a higher prevalence of osteoporosis, ${ }^{12}$ which increases the risk of fall-related fractures and its complications, including hospitalizations. Such hospital admissions can be even more harmful for patients with COPD due to respiratory system susceptibility and preexisting reduction of peripheral muscle strength, physical activity level, and exercise capacity. ${ }^{3}$ For these reasons, the topic is currently a field of interest.

To choose the appropriate rehabilitative approach, a deeper scientific knowledge about the profile of COPD patients with poor balance is necessary. To date, some studies have shown that people with COPD have impaired body balance when compared with healthy individuals 5,6,13-16; however, this information is not fully established yet. Balance impairment was demonstrated by stabilographic analysis $^{5,6,13}$ or functional balance tests, ${ }^{5,14-16}$ but both types of assessment in the same sample are scarce. Moreover, it is unknown whether there are differences in static and functional balance according to sex as well as among patients with different stages of disease severity.

Therefore, the aim of the present study was to compare static and functional balance between individuals with

REVAL-Rehabilitation Research Center, BIOMED-Biomedical Research Institute, Faculty of Medicine and Life Sciences, Hasselt University, Diepenbeek, Belgium.

This study was supported by National Counsel of Technological and Scientific Development (CNPq), Brazil, Grant 476238/2012-9-Universal 14/2012. The authors have disclosed no conflicts of interest.

Ms de Castro and Ms Ribeiro contributed equally to this work.

Correspondence: Vanessa S Probst PhD, Laboratory of Research in Respiratory Physiotherapy (LFIP), Physiotherapy Department, Londrina State University (UEL), Avenida Robert Koch, 60-Vila Operária, 86038350, Londrina, Paraná, Brasil. E-mail: vanessaprobst@gmail.com.

DOI: $10.4187 /$ respcare.04749

\section{QUICK LOOK}

\section{Current knowledge}

Recent studies have suggested that individuals with COPD have impaired balance, potentially increasing the risk of falls. However, little is known about the profile of people with COPD who present poor balance, especially concerning differences related to sex and disease severity.

\section{What this paper contributes to our knowledge}

Subjects with COPD have worse functional and static balance in comparison with healthy individuals. However, they do not necessarily have balance deficits and risk of falling according to the functional test performed. Men performed better in the functional balance test than women, whereas women presented better static balance in comparison with men. Balance was not related to disease severity.

COPD and healthy controls. In addition, we also sought to determine possible differences between sexes and among different levels of disease severity.

\section{Methods}

\section{Study Design and Sample}

This cross-sectional study was conducted from July 2011 to January 2014. The total sample was composed of 72 participants, 47 individuals with COPD and 25 subjects without COPD (control group).

Inclusion criteria for subjects with COPD were: diagnosis of COPD according to the Global Initiative for Obstructive Lung Disease (GOLD) ${ }^{17}$; stable disease (no severe exacerbations in the prior 3 months); age $\geq 50$ y old; absence of severe comorbidities that could interfere in the assessments; absence of balance disorders (eg, labyrinthitis or benign paroxysmal positional vertigo); absence of previous lower-limb fractures; absence of severe audiovisual disorders; and absence of regular physical exercise practice in the last 6 months. The control group had the same inclusion criteria except for the diagnosis of COPD. Those who were unable to either understand or perform any procedure or who requested to leave the study for any reason were excluded. The study was approved by the Research Ethics Committee of the University of Northern Parana (UNOPAR), and all participants gave written informed consent. 


\section{Procedures}

Anthropometric Data. Weight and height were measured, and body mass index (BMI) was then calculated $\left(\mathrm{kg} / \mathrm{m}^{2}\right)$. Weight was assessed using a portable digital scale (Welmy, Santa Bárbara d'Oeste, Brazil), and height was assessed by an anthropometer (Sanny, São Bernardo do Campo, Brazil.).

Pulmonary Function. Spirometry was performed to evaluate pulmonary function (Pony FX spirometer, Cosmed, Rome, Italy). The test was carried out according to international guidelines, ${ }^{18}$ and the reference values for the Brazilian population were applied. ${ }^{19}$

Disease Severity. Based on spirometry, subjects with COPD were separated according to GOLD classification for disease severity: GOLD I, mild (FEV $1 \geq 80 \%$ predicted); GOLD II, moderate (FEV 1 50-79\% predicted); GOLD III, severe $\left(\mathrm{FEV}_{1} 30-49 \%\right.$ predicted); and GOLD IV, very severe $\left(\mathrm{FEV}_{1}<30 \%\right.$ predicted). ${ }^{17}$ In addition, the BODE (body mass index, air-flow obstruction, dyspnea, and exercise capacity) index was also used to classify disease severity. ${ }^{20}$ The score ranges from 0 to 10 , and higher values indicate worse disease severity. ${ }^{20}$ Subjects were classified in quartiles according to the score obtained: I (score 0-2), II (score 3-4), III (score 5-6), and IV (score 7-10). Two groups were further separated for analysis: less severe disease (quartiles I and II) and more severe disease (quartiles III and IV).

Static Balance. Static balance was evaluated using a force platform (BIOMEC400, EMG System of Brazil, São José dos Campos, Brazil), which is a reliable instrument for stabilographic measures in both older and young adults. ${ }^{21}$ All participants were assessed in a one-legged stance, a position considered more predictive of falls. ${ }^{22,23}$ The variables used for analyses were center of pressure displacement area, center of pressure displacement velocity in anterior-posterior direction, and center of pressure displacement velocity in medial-lateral direction. Participants performed 3 trials of $30 \mathrm{~s}$ in a one-legged stance, and the average was used for statistical analysis. ${ }^{21}$

Functional Balance. Functional balance was assessed by the Timed Up and Go test, ${ }^{24}$ which has been considered a simple screening test for measuring the risk of falling among older adults. ${ }^{25}$ In this test, participants are requested to stand up from a standardized armchair, walk at their usual speed a distance of $3 \mathrm{~m}$, turn, walk back to the chair, and sit down again. ${ }^{24}$ During the test, physical assistance is not given, subjects wear their usual footwear, and walking aids and oxygen are allowed, if necessary. ${ }^{24}$ The test was performed twice, and the best result was used for analysis. ${ }^{26}$

Functional Exercise Capacity. The 6-min walk distance (6MWD) was used to assess functional exercise capacity. It was performed according to European Respiratory Society and American Thoracic Society guidelines, ${ }^{27,28}$ in a 30-m corridor. The reference values used were previously developed for Brazilians by Britto et al. ${ }^{29}$

Peripheral Muscle Strength. Peripheral muscle strength of subjects with COPD was evaluated using a portable dynamometer (microFET2, Hoggan Health Industries, West Jordan, Utah) attached to multistation equipment (Multigym-CRW 1000, Embreex, Brusque, Brazil). The isometric quadriceps maximal voluntary contraction of the dominant lower limb ${ }^{30}$ was assessed, and the best of 3 acceptable and reproducible measurements was used for analysis. ${ }^{31}$ The reference values were described previously by Neder et al. ${ }^{32}$

\section{Statistical Analysis}

Statistical analysis was performed using GraphPad Prism 6.0 (GraphPad Software, San Diego, California). The Shapiro-Wilk test was used to verify the normality of data distribution. The unpaired Student $t$ test or Mann-Whitney test was used for intergroup comparisons. The chi-square (with or without Yates correction) or Fisher exact test was used to compare the sex distribution between groups. The comparisons according to disease severity were performed using the one-way analysis of variance or Kruskal-Wallis test (Tukey or Dunn post-test, respectively). The Spearman or Pearson correlation coefficients were used to identify correlations between general characteristics and body balance variables. All tests were 2-tailed, and the statistical significance was set as $P<.05$.

The power of the study was calculated retrospectively (GPower 3.1, Heinrich-Heine-University, Düsseldorf, Germany). Based on the difference found in time spent to perform the Timed Up and Go test between the COPD group and control group (COPD group $[n=47]: 10.3 \pm 1.8 \mathrm{~s}$ vs control group $[n=25]: 8.5 \pm 1.3 \mathrm{~s}$ ) and the difference found in the center of pressure displacement area in a one-legged stance (COPD group [ $n=39]: 11.6 \pm 4.0 \mathrm{~cm}^{2}$ vs control group $\left[n=25\left[: 9.3 \pm 1.9 \mathrm{~cm}^{2}\right.\right.$ ), considering an $\alpha$ of .05 , the sample size has a power $>80 \%$ for both.

\section{Results}

The general characteristics of the 72 studied participants are shown in Table 1. Mean age, BMI, and sex ratio were comparable between groups. As expected, subjects with COPD presented worse values of pulmonary function and 
Table 1. General Characteristics of the Participants

\begin{tabular}{|c|c|c|c|}
\hline Variables & $\begin{array}{l}\text { COPD } \\
(n=47)\end{array}$ & $\begin{array}{l}\text { Control } \\
(n=25)\end{array}$ & $P$ \\
\hline Male/female sex, $n$ & $27 / 20$ & $15 / 10$ & .83 \\
\hline Age, mean $\pm \mathrm{SD} y$ & $68 \pm 5$ & $66 \pm 8$ & .28 \\
\hline Weight, mean $\pm \mathrm{SD} \mathrm{kg}$ & $73 \pm 12$ & $70 \pm 15$ & .34 \\
\hline Height, mean $\pm \mathrm{SD} \mathrm{m}$ & $1.62 \pm 0.09$ & $1.63 \pm 0.08$ & .89 \\
\hline $\mathrm{BMI}$, mean $\pm \mathrm{SD} \mathrm{kg} / \mathrm{m}^{2}$ & $26 \pm 5$ & $28 \pm 5$ & .17 \\
\hline $\begin{array}{l}\mathrm{FEV}_{1} \text {, mean } \pm \mathrm{SD} \% \\
\text { predicted }\end{array}$ & $45 \pm 15$ & $87 \pm 17$ & $<.001$ \\
\hline $\mathrm{FVC}$, mean $\pm \mathrm{SD} \%$ predicted & $63 \pm 13$ & $83 \pm 13$ & $<.001$ \\
\hline $\mathrm{FEV}_{1} / \mathrm{FVC}$, mean $\pm \mathrm{SD}$ & $0.54 \pm 0.10$ & $0.82 \pm 0.6$ & $<.001$ \\
\hline $6 \mathrm{MWD}$, mean $\pm \mathrm{SD} \mathrm{m}$ & $481 \pm 81$ & $587 \pm 74$ & $<.001$ \\
\hline $\begin{array}{l}\text { 6MWD, mean } \pm \text { SD } \% \\
\text { predicted }\end{array}$ & $89 \pm 14$ & $110 \pm 11$ & $<.001$ \\
\hline $\begin{array}{l}\text { QMVC, mean } \pm \text { SD newton- } \\
\text { meters }\end{array}$ & $89 \pm 29$ & ND & NA \\
\hline $\begin{array}{l}\text { QMVC, mean } \pm \text { SD } \% \\
\text { predicted }\end{array}$ & $75 \pm 21$ & ND & NA \\
\hline BODE, mean \pm SD score & $3.8 \pm 1.8$ & NA & NA \\
\hline $\mathrm{MRC}$, mean $\pm \mathrm{SD}$ score & $2.7 \pm 1.2$ & NA & NA \\
\hline $\begin{array}{l}\text { BMI = body mass index } \\
6 \mathrm{MWD}=6 \text {-min walk distance } \\
\mathrm{QMVC}=\text { isometric quadriceps maximal } \\
\mathrm{NA}=\text { not applicable } \\
\mathrm{ND}=\text { no data available } \\
\mathrm{BODE}=\text { body mass index, air-flow obstr } \\
\mathrm{MRC}=\text { Medical Research Council scale }\end{array}$ & untary contraction & kercise capacity & \\
\hline
\end{tabular}
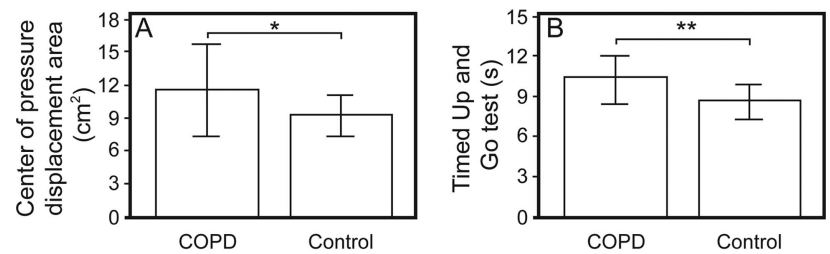

Fig. 1. Comparison of static balance $(A)$ and functional balance $(B)$ between subjects with COPD and healthy control individuals. Data are presented as mean $\pm \mathrm{SD}$. ${ }^{\star} P=.01 ;{ }^{\star} P<.001$.

functional exercise capacity in comparison with the control group.

Regarding static balance, individuals with COPD presented a greater center of pressure displacement area in one-legged stance when compared with the control group (Fig. 1A). No differences were found between groups when analyzing the center of pressure displacement velocity in the anterior-posterior direction (control group: $3.5 \pm 1.5 \mathrm{~cm} / \mathrm{s}$ vs COPD group: $3.8 \pm 1.3 \mathrm{~cm} / \mathrm{s}, P=.19$ ) and the center of pressure displacement velocity in the medial-lateral direction (control group: $3.7 \pm 1.7 \mathrm{~cm} / \mathrm{s} \mathrm{vs}$ COPD group: $3.6 \pm 0.9 \mathrm{~cm} / \mathrm{s}, P=.48$ ). Eight participants $(17 \%)$ from the COPD group were not able to remain in the one-legged stance for $30 \mathrm{~s}$, whereas all subjects in the control group completed the test. Subjects with COPD also
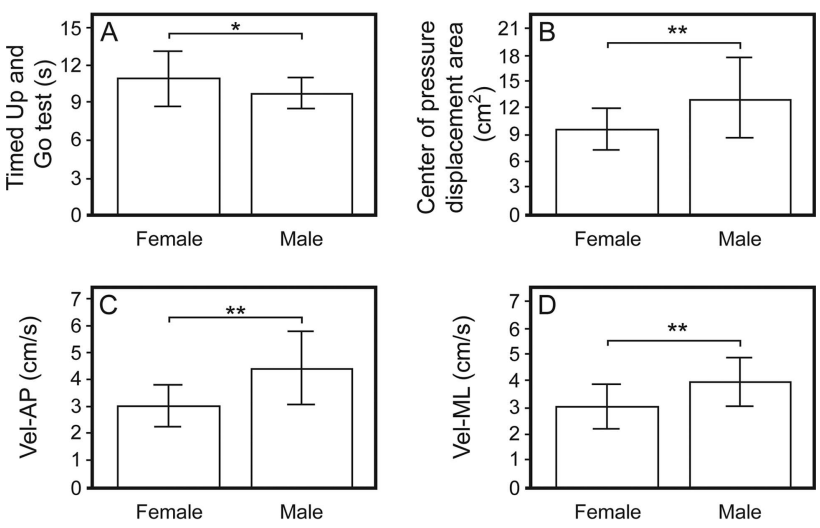

Fig. 2. Comparison of functional balance $(A)$ and static balance in a one-legged stance (B, C, and $D)$ according to sex in subjects with COPD. Vel-AP: center of pressure displacement velocity in the anterior-posterior direction; Vel-ML: center of pressure displacement velocity in the medial-lateral direction. Data are presented as mean \pm SD. ${ }^{\star} P=.03 ;{ }^{\star \star} P<.005$.

presented worse functional balance in comparison with the control group (Fig. 1B).

When analyzing functional balance according to sex, women with COPD performed worse in the Timed Up and Go test in comparison with men (Fig. 2A). Static balance was also different between sexes, since men presented a greater center of pressure displacement area and velocity in the one-legged stance compared with women (Fig. 2, B, $\mathrm{C}$, and D). Men and women presented comparable weight, BMI, pulmonary function, isometric quadriceps maximal voluntary contraction (predicted), and 6MWD (absolute and predicted). There were differences in age (men: $68 \pm 8.0$ y vs women: $63 \pm 5.7 \mathrm{y}, P=.01$ ), height (men: $1.67 \pm 0.07 \mathrm{~m}$ vs women: $1.56 \pm 0.06 \mathrm{~m}, P<.001$ ), and absolute isometric quadriceps maximal voluntary contraction (men: $102 \pm 28$ newton-meters vs women: $73 \pm 21$ newton-meters, $P=.001$ ).

These differences were not observed in the control group for both functional and static balance (Timed Up and Go test [males: $8.4 \pm 1.3 \mathrm{~s}$ vs females: $8.8 \pm 1.3 \mathrm{~s}, P=.45$ ]; center of pressure displacement area [males: $9.5 \pm 1.6 \mathrm{~cm}^{2}$ vs females: $\left.8.9 \pm 2.1 \mathrm{~cm}^{2}, P=.38\right]$; center of pressure displacement velocity in the anterior-posterior direction [males: $3.4 \pm 1.2 \mathrm{~cm} / \mathrm{s}$ vs females: $3.6 \pm 1.8 \mathrm{~cm} / \mathrm{s}, P>.99$ ]; and center of pressure displacement velocity in the medial-lateral direction [males: $3.6 \pm 0.8 \mathrm{~cm} / \mathrm{s}$ vs females: $3.8 \pm 2.2 \mathrm{~cm} / \mathrm{s}, P=.55])$. Men and women presented comparable weight, BMI, pulmonary function, and predicted 6MWD. There were differences in absolute 6MWD (men: $625 \pm 66 \mathrm{~m}$ vs women: $526 \pm 34 \mathrm{~m}$, $P=.002)$ and height (men: $1.67 \pm 0.03 \mathrm{~m}$ vs women: $1.54 \pm 0.07 \mathrm{~m}, P<.001)$. Functional and static balance did not differ among subgroups separated according to GOLD stages and BODE scores for disease severity (Table 2). 
Table 2. Comparison of General Characteristics and Functional and Static Balance According to Global Initiative for Obstructive Lung Disease and BODE Index Criteria for Disease Severity

\begin{tabular}{|c|c|c|c|c|c|c|c|}
\hline \multirow[b]{2}{*}{ Variables } & \multicolumn{3}{|c|}{ GOLD } & \multirow[b]{2}{*}{$P$} & \multicolumn{2}{|c|}{ BODE } & \multirow[b]{2}{*}{$P$} \\
\hline & II & III & IV & & $\begin{array}{l}\text { Quartiles } \\
\text { I and II }\end{array}$ & $\begin{array}{l}\text { Quartiles } \\
\text { III and IV }\end{array}$ & \\
\hline Male/female sex, $n$ & $9 / 7$ & $12 / 9$ & $6 / 3$ & .86 & $20 / 12$ & $7 / 8$ & .35 \\
\hline Age, mean \pm SD y & $67 \pm 7.4$ & $66 \pm 8.2$ & $66 \pm 7.7$ & .92 & $66 \pm 7.7$ & $67 \pm 7.6$ & .76 \\
\hline $\mathrm{BMI}$, mean $\pm \mathrm{SD} \mathrm{kg} / \mathrm{m}^{2}$ & $28 \pm 4$ & $25 \pm 5$ & $28 \pm 3$ & .051 & $26 \pm 4.4$ & $26 \pm 5.8$ & .81 \\
\hline $\mathrm{FEV}_{1} / \mathrm{FVC}$, mean $\pm \mathrm{SD}$ & $0.62 \pm 0.06$ & $0.53 \pm 0.07 *$ & $0.42 \pm 0.07 * \dagger$ & $<.001$ & $0.58 \pm 0.08$ & $0.47 \pm 0.09$ & $<.001$ \\
\hline $\mathrm{FEV}_{1}$, mean $\pm \mathrm{SD} \%$ predicted & $59 \pm 5$ & $40 \pm 6^{*}$ & $25 \pm 3^{* \dagger}$ & $<.001$ & $50 \pm 13.3$ & $33 \pm 10.3$ & $<.001$ \\
\hline $6 \mathrm{MWD}$, mean $\pm \mathrm{SD} \mathrm{m}$ & $494 \pm 67$ & $493 \pm 78$ & $434 \pm 103$ & .29 & $510 \pm 47$ & $421 \pm 103$ & $<.001$ \\
\hline $6 \mathrm{MWD}$, mean $\pm \mathrm{SD} \%$ predicted & $93 \pm 12$ & $90 \pm 13$ & $81 \pm 18$ & .28 & $94 \pm 8$ & $79 \pm 18$ & $<.001$ \\
\hline QMVC, mean \pm SD newton-meters & $91 \pm 29$ & $90 \pm 30$ & $87 \pm 31$ & .93 & $98 \pm 28$ & $70 \pm 20$ & $<.001$ \\
\hline $\mathrm{QMVC}$, mean $\pm \mathrm{SD} \%$ predicted & $73 \pm 23$ & $78 \pm 18$ & $73 \pm 24$ & .11 & $79 \pm 21$ & $66 \pm 16$ & .01 \\
\hline $\mathrm{MRC}$, mean $\pm \mathrm{SD}$ score & $2.5 \pm 1.5$ & $2.7 \pm 1.1$ & $5.5 \pm 1.2 * \dagger$ & $<.001$ & $2.1 \pm 0.9$ & $4.0 \pm 0.4$ & $<.001$ \\
\hline $\mathrm{TUG}$, mean $\pm \mathrm{SD} \mathrm{s}$ & $10 \pm 2.1$ & $10 \pm 1.6$ & $11 \pm 1.7$ & .23 & $10 \pm 1.7$ & $11 \pm 1.9$ & .33 \\
\hline $\mathrm{COP}$-area, mean $\pm \mathrm{SD} \mathrm{cm}{ }^{2}$ & $11.5 \pm 3.0$ & $12.0 \pm 5.1$ & $10.7 \pm 3.5$ & .99 & $12.0 \pm 4.1$ & $10.3 \pm 3.8$ & .23 \\
\hline Vel-AP, mean $\pm \mathrm{SD} \mathrm{cm} / \mathrm{s}$ & $3.6 \pm 0.9$ & $3.9 \pm 1.6$ & $4.0 \pm 1.7$ & .67 & $3.9 \pm 1.4$ & $3.6 \pm 1.2$ & .50 \\
\hline Vel-ML, mean $\pm \mathrm{SD} \mathrm{cm} / \mathrm{s}$ & $3.6 \pm 0.5$ & $3.7 \pm 1.2$ & $3.4 \pm 1.7$ & .79 & $3.7 \pm 0.9$ & $3.3 \pm 0.9$ & .20 \\
\hline $\begin{array}{l}\text { Only one subject was classified as GOLD I and } t \\
\text { * Significant difference in comparison with the G } \\
\dagger \text { Significant difference in comparison with the G } \\
30 \% \leq \text { FEV } \text { G }_{1}<50 \% \text { predicted; GOLD IV: FEV } \\
\text { GOLD = Global Initiative for Obstructive Lung I } \\
\text { BODE = body mass index, air-flow obstruction, } \\
\text { BMI = body mass index } \\
\text { 6MWD = 6-min walk distance } \\
\text { QMVC = isometric quadriceps maximal voluntar } \\
\text { MRC = Medical Research Council scale } \\
\text { TUG = Timed Up and Go test } \\
\text { COP-area = center of pressure displacement area } \\
\text { Vel-AP = center of pressure displacement velocit } \\
\text { Vel-ML = center of pressure displacement veloci }\end{array}$ & $\begin{array}{l}\text { was excluded from } \\
\text { D II group accordin } \\
\text { D III group accordi } \\
30 \% \text { predicted). } \\
\text { ease } \\
\text { pnea, and exercise } \\
\text { ontraction }\end{array}$ & $\begin{array}{l}\text { analyses. } \\
\text { post hoc test. } \\
\text { o post hoc test (GOL } \\
\text { city }\end{array}$ & $50 \% \leq \mathrm{FEV}_{1}<80$ & edicted; GO & III: & & \\
\hline
\end{tabular}

A secondary analysis was done to compare the general characteristics and functional and static balance of participants with COPD who were able to perform the onelegged stance test with participants who were not (Table 3 ). This sub-analysis showed that those not able to perform the one-legged stance test were older and had a higher BMI and worse functional exercise performance.

In the COPD group, there was a moderate correlation between age and all parameters related to center of pressure (Fig. 3, A, B, and C). Functional balance correlated to height, absolute 6MWD, and absolute isometric quadriceps maximal voluntary contraction (Fig. 4, A, B, and C).

\section{Discussion}

The present study demonstrated that both static and functional balance are more impaired in people with COPD in comparison with healthy individuals. In the COPD group, men performed better in the functional balance test than women, whereas women presented a better static balance in comparison with men. Moreover, balance performance was comparable among the groups classified according to disease severity.

\section{Comparison Between COPD and Control Groups}

As in this study, Smith et $\mathrm{al}^{6}$ observed that people with COPD have worse static balance in comparison with healthy volunteers. Using a force platform, the authors verified a larger center of pressure range in the medial-lateral direction in the COPD group. Our study found a larger center of pressure displacement area in individuals with COPD, but no differences were verified in the velocity of this displacement in both directions (anterior-posterior and medial-lateral). The different parameters used for analysis make it difficult to compare the studies. Smith et $\mathrm{al}^{6} \mathrm{cal}-$ culated the range of COP displacement in both directions (ie, maximal amplitude of the path of the COP), whereas in the present study, the area of displacement (95\% ellipse area) and its velocity were used for analyses.

Other studies have shown similar results (ie, worse balance in people with COPD when compared with healthy individuals) despite using different assessment methodologies. ${ }^{6,9,13-15}$ Some authors have used objective tests, such as force platform, ${ }^{6}$ force platform associated with proprioceptive perturbation, ${ }^{13}$ and the Sensory Organization test, ${ }^{15}$ whereas others have chosen functional tests (eg, the 
Table 3. Comparison of General Characteristics and Functional and Static Balance Between Subjects With COPD Who Performed or Did Not Perform the One-Legged Stance Test

\begin{tabular}{|c|c|c|c|}
\hline Variables & $\begin{array}{l}\text { With OLS } \\
(n=39)\end{array}$ & $\begin{array}{l}\text { Without OLS } \\
\quad(n=8)\end{array}$ & $P$ \\
\hline Male/female sex, $n$ & $22 / 17$ & $5 / 3$ & .94 \\
\hline Age, mean \pm SD y & $65 \pm 7.2$ & $73 \pm 5.9$ & .005 \\
\hline $\mathrm{BMI}$, mean $\pm \mathrm{SD} \mathrm{kg} / \mathrm{m}^{2}$ & $26 \pm 4$ & $30 \pm 6$ & .002 \\
\hline $\mathrm{FEV}_{1} / \mathrm{FVC}$, mean $\pm \mathrm{SD}$ & $0.55 \pm 0.09$ & $0.54 \pm 0.01$ & .97 \\
\hline $\mathrm{FEV}_{1}$, mean $\pm \mathrm{SD} \%$ predicted & $44 \pm 15$ & $46 \pm 15$ & .76 \\
\hline $6 \mathrm{MWD}$, mean $\pm \mathrm{SD} \mathrm{m}$ & $494 \pm 72$ & $420 \pm 97$ & .02 \\
\hline $\begin{array}{l}6 \mathrm{MWD}, \text { mean } \pm \mathrm{SD} \% \\
\text { predicted }\end{array}$ & $91 \pm 13$ & $82 \pm 17$ & .065 \\
\hline $\begin{array}{l}\text { QMVC, mean } \pm \mathrm{SD} \\
\text { newton-meters }\end{array}$ & $91 \pm 29$ & $83 \pm 28$ & .52 \\
\hline $\begin{array}{l}\mathrm{QMVC}, \text { mean } \pm \mathrm{SD} \% \\
\text { predicted }\end{array}$ & $76 \pm 21$ & $68 \pm 19$ & .31 \\
\hline BODE, mean \pm SD score & $3.8 \pm 1.8$ & $3.9 \pm 2.2$ & .91 \\
\hline $\mathrm{MRC}$, mean $\pm \mathrm{SD}$ score & $2.7 \pm 1.1$ & $2.6 \pm 1.3$ & .68 \\
\hline TUG, mean $\pm \mathrm{SD} \mathrm{s}$ & $10 \pm 1.9$ & $11 \pm 1.3$ & .10 \\
\hline $\begin{array}{l}\text { OLS }=\text { one-legged stance } \\
\text { BMI }=\text { body mass index } \\
\text { 6MWD = 6-min walk distance } \\
\text { QMVC = isometric quadriceps maximal } \\
\text { BODE }=\text { body mass index, air-flow obstr } \\
\text { MRC = Medical Research Council scale } \\
\text { TUG }=\text { Timed Up and Go test }\end{array}$ & $\begin{array}{l}\text { untary contraction } \\
\text { ion, dyspnea, and }\end{array}$ & ercise capacity & \\
\hline
\end{tabular}

Balance Evaluation Systems test, ${ }^{14}$ Timed Up and Go test, and Berg Balance scale). ${ }^{9}$ In this context, the present study is novel, since balance was evaluated in 2 different ways, static (objective) and functional. This combined methodology reinforces our findings and, consequently, the statement that people with COPD have worse balance in comparison to people without the disease, as demonstrated in a recently published systematic review. ${ }^{33}$

Similarly to this study, Butcher et $\mathrm{al}^{5}$ used static and functional balance assessments. The authors compared 3 groups: subjects with COPD who required supplemental oxygen, subjects with COPD who did not require supplemental oxygen, and healthy control subjects. In their study, healthy individuals performed better in some functional balance tests in comparison with the other groups composed of people with COPD; however, the static balance analysis showed differences only between control subjects and people with COPD requiring supplemental oxygen (ie, those with more severe disease). In the present study, participants with COPD presented worse performance in static balance regardless of disease severity. This difference may be explained by the choice of static balance tasks. The one-legged stance seems to be more challenging, and for this reason, it might have a higher potential to discriminate those with and without balance impairment.

\section{Differences According to Disease Severity}

Butcher et $\mathrm{al}^{5}$ observed a moderate correlation between balance and measures of disease severity, as determined through spirometry. In another study, there was high correlation between BODE index score and functional balance assessed by the Tinetti scale. ${ }^{16}$ In the present study, there was no correlation between balance and pulmonary function or between balance and BODE index score. In addition, static and functional balance did not differ among subgroups separated according to GOLD and BODE criteria for disease severity. A possible explanation for this finding is the relative preserved balance of our sample, taking into account the performance in the Timed Up and Go test. Shumway-Cook et $\mathrm{al}^{25}$ found that older adults who take $>14$ s to complete this test have poor balance and are at risk of falling. Therefore, even performing worse in the Timed Up and Go test in comparison with healthy controls, the COPD group presented a relatively preserved functional balance according to this cut-off value, since only 3 participants $(6.4 \%)$ took $>14$ s to complete the Timed Up and Go test. This performance may be related to exercise capacity. Despite being significantly worse than healthy controls, the mean distance walked in the 6MWD was $481 \mathrm{~m}$, which corresponds to almost $90 \%$ of the predicted value. Furthermore, functional exercise capacity moderately correlated to functional balance of subjects with COPD in the present study.

\section{Differences According to Sex}

In the present study, men performed better in the Timed Up and Go test than women. This finding can be partially explained by their superior peripheral muscle force (absolute values). Indeed, a well-preserved strength of lower limbs may facilitate the moment of standing up and sitting on the chair during the test. Men were also significantly taller, which might have contributed to this result, since a greater stride length can influence the time to complete the test. Moreover, although modestly, the Timed Up and Go test negatively correlated with peripheral muscle force and height in this sample. It is important to mention that the only 3 participants who took longer than $14 \mathrm{~s}$ to finish the Timed Up and Go test were women. Since the Timed Up and Go test is a functional test (ie, it reflects an activity of daily life), it would be reasonable to hypothesize that women are more susceptible to repercussions of this poorer performance in real life. In the prospective study conducted by Roig et al, ${ }^{10}$ most subjects with COPD considered as "fallers" were women, which corroborates with this hypothesis.

On the other hand, women performed better in the static balance test than men. They had better performance despite presenting reduced muscle strength in comparison 

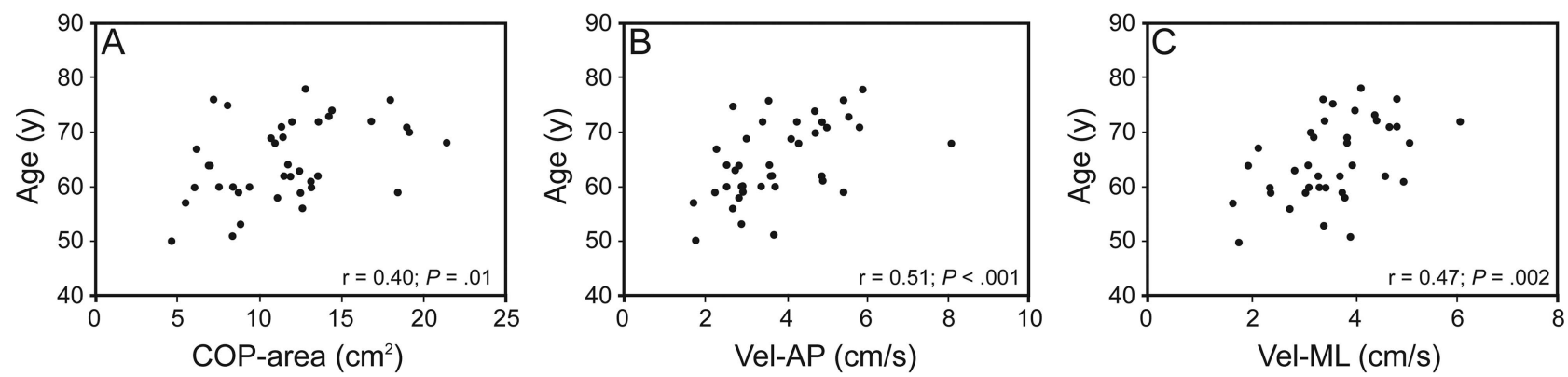

Fig. 3. Correlation between age and center of pressure displacement area (COP-area) (A), center of pressure displacement velocity in the anterior-posterior direction (Vel-AP) (B), and center of pressure displacement velocity in the medial-lateral direction (Vel-ML) (C).
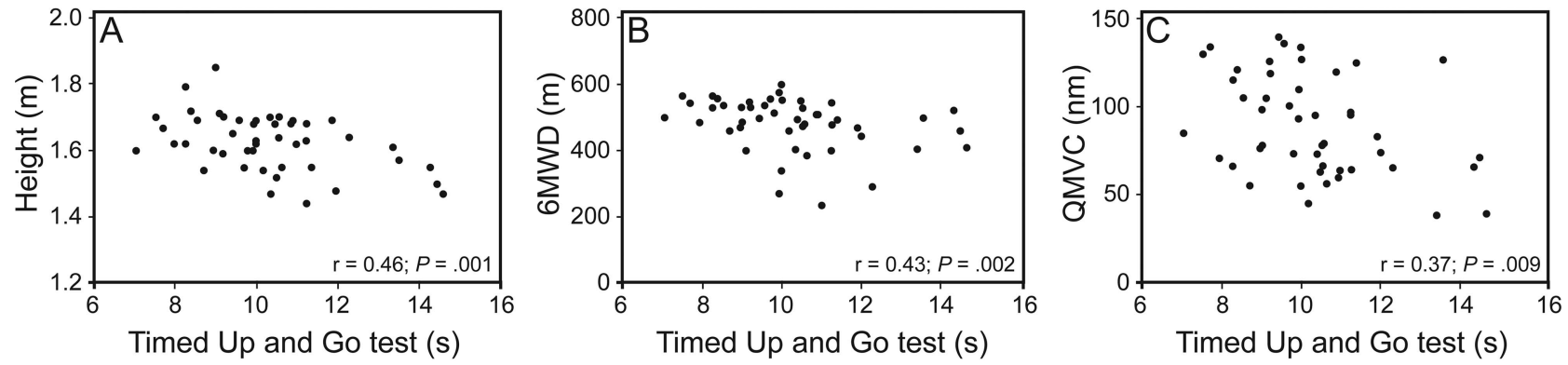

Fig. 4. Correlation between Timed Up and Go test and height (A), 6-min walk test distance (6MWD) (B), and isometric quadriceps maximal voluntary contraction (QMVC) (C).

with men, which suggests that other mechanisms might be involved and more related to motor control. In another study, ${ }^{34}$ the authors used the same force platform, task, and parameters to evaluate the balance of elderly subjects with and without osteoporosis. They found that men presented poorer balance in comparison with women for all parameters related to center of pressure, regardless of disease. The differences in physical performance between men and women are well known in the literature and have a relationship with anthropometric characteristics and morphology of each sex. ${ }^{35}$ Also, between-sex differences in an activity pool of vestibular, proprioceptive, and visual systems have already been reported. ${ }^{36,37}$ During development of children and teenagers, the vestibular system and feedback/feedforward mechanisms develop later in boys than in girls, ${ }^{37}$ which might influence postural control during the aging process. Elderly men would not integrate these 3 systems (vestibular, proprioceptive, and visual) as effectively as women matched by age. ${ }^{36}$ In addition, the daily activities of men and women are different, and this may influence in some physical abilities, including balance. Elderly women remain significantly longer standing than men. ${ }^{38}$ This posture is probably stimulated by a greater demand that women perform household activities often carried out in a standing position, such as washing, ironing, and cooking. ${ }^{38}$ These activities, which are present in higher amounts in women's daily lives, can also exert influence on their balance.

\section{Mechanisms of Balance in COPD}

In the study developed by Roig et al ${ }^{15}$ people with COPD performed worse in the Sensory Organization test than healthy volunteers, despite the peripheral muscle force condition and physical activity level. Janssens et al ${ }^{13}$ concluded that individuals with COPD have proprioceptive alterations probably related to an impaired postural contribution of the inspiratory muscle to trunk stability. In the present study, static balance correlated with age only, whereas functional balance had a correlation with peripheral muscle force and exercise capacity. It is possible to note that data available in the literature concerning the mechanisms of balance deterioration in COPD are inconsistent, exposing the need for further research in this field.

\section{Limitations, Contributions, and Future Research}

The lack of a group composed of people with COPD classified as GOLD I can be considered a limitation, since it hinders the external validity of the present results. However, these individuals are usually asymptomatic and rarely seek medical attention, making it difficult to form a group. As another limitation, it is possible to point out the absence of peripheral muscle force evaluation in the control group. The explanation is the recruitment source of healthy control subjects; they came from a parallel study in which 


\section{Static and Functional Balance in Individuals With COPD}

muscle force was not assessed. Although a comparison between the COPD and control groups was not possible, the peripheral muscle force evaluation was helpful to understand the possible mechanisms of balance control in COPD.

The present study reinforces the statement that people with COPD have worse balance in comparison with healthy individuals, which was demonstrated by analyzing static and functional balance. Despite this, they do not necessarily have a balance deficit and risk of falling according to the functional test performed. This study adds new knowledge about the differences in balance performance according to sex and disease severity. Finally, it contributes to elucidating the mechanisms of balance control in COPD.

Several aspects of balance in COPD still need further research. For instance, the mechanisms involved in balance deficits are inconsistent in the literature. The profile of individuals with COPD who present balance disorders and risk of falling remains partially unknown, making it difficult to guide clinicians on which patients should attend specific training for balance during pulmonary rehabilitation. Furthermore, it is still not clear how severe balance impairments must be to indicate balance interventions during pulmonary rehabilitation in individuals with COPD.

\section{Conclusions}

Individuals with COPD had worse functional and static balance in comparison with healthy controls. Sex can mediate these results, depending on the type of balance evaluation (force platform or functional test), since men presented a better functional balance than women but poorer postural control on force platform. Finally, balance was not related to disease severity.

\section{REFERENCES}

1. Raherison C, Girodet PO. Epidemiology of COPD. Eur Respir Rev 2009;18(114):213-221.

2. Bárbara C, Rodrigues F, Dias H, Cardoso J, Almeida J, Matos MJ, et al. Chronic obstructive pulmonary disease prevalence in Lisbon, Portugal: the burden of obstructive lung disease study Rev Port Pneumol 2013;19(3):96-105.

3. Spruit MA, Singh SJ, Garvey C, ZuWallack R, Nici L, Rochester C, et al. An Official American Thoracic Society/European Respiratory Society Statement: key concepts and advances in pulmonary rehabilitation. Am J Respir Crit Care Med 2013;188(8):e13-e64.

4. Beauchamp MK, Brooks D, Goldstein RS. Deficits in postural control in individuals with COPD: emerging evidence for an important secondary impairment. Multidiscip Respir Med 2010;5(6):417-421.

5. Butcher SJ, Meshke JM, Sheppard MS. Reductions in functional balance, coordination, and mobility measures among patients with stable chronic obstructive pulmonary disease. J Cardiopulm Rehabil 2004;24(4):274-280.

6. Smith MD, Chang AT, Seale HE, Walsh JR, Hodges PW. Balance is impaired in people with chronic obstructive pulmonary disease. Gait Posture 2010;31(4):456-460.
7. Freitas SM, Wieczorek SA, Marchetti PH, Duarte M. Age-related changes in human postural control of prolonged standing. Gait Posture 2005;22(4):322-330

8. Roig M, Eng JJ, Road JD, Reid WD. Falls in patients with chronic obstructive pulmonary disease: a call for further research. Respir Med 2009;103(9):1257-1269.

9. Beauchamp MK, Hill K, Goldstein RS, Janaudis-Ferreira T, Brooks D. Impairments in balance discriminate fallers from non-fallers in COPD. Respir Med 2009;103(12):1885-1891.

10. Roig M, Eng JJ, MacIntyre DL, Road JD, FitzGerald JM, Burns J, Reid WD. Falls in people with chronic obstructive pulmonary disease: an observational cohort study. Respir Med 2011;105(3):461469.

11. Sibley KM, Voth J, Munce SE, Straus SE, Jaglal SB. Chronic disease and falls in community-dwelling Canadians over 65 years old: a population-based study exploring associations with number and pattern of chronic conditions. BMC Geriatr 2014;14:22.

12. Sabit R, Bolton CE, Edwards PH, Pettit RJ, Evans WD, McEniery $\mathrm{CM}$, et al. Arterial stiffness and osteoporosis in chronic obstructive pulmonary disease. Am J Respir Crit Care Med 2007;175(12):12591265.

13. Janssens L, Brumagne S, McConnell AK, Claeys K, Pijnenburg M, Burtin $\mathrm{C}$, et al. Proprioceptive changes impair balance control in individuals with chronic obstructive pulmonary disease. PLoS One 2013;8(3):e57949.

14. Beauchamp MK, Sibley KM, Lakhani B, Romano J, Mathur S, Goldstein RS, Brooks D. Impairments in systems underlying control of balance in COPD. Chest 2012;141(6):1496-1503.

15. Roig M, Eng JJ, Macintyre DL, Road JD, Reid WD. Postural control is impaired in people with COPD: an observational study. Physiother Can 2011;63(4):423-431

16. Rocco CCM, Sampaio LMM, Stirbulov R, Corrêa JCF. Neurophysiological aspects and their relationship to clinical and functional impairment in patients with chronic obstructive pulmonary disease. Clinics 2011;66(1):125-129.

17. Vestbo J, Hurd SS, Agustí AG, Jones PW, Vogelmeier C, Anzueto A, et al. Global strategy for the diagnosis, management, and prevention of chronic obstructive pulmonary disease: GOLD executive summary. Am J Respir Crit Care Med 2013;187(4):347-365.

18. Miller MR, Hankinson J, Brusasco V, Burgos F, Casaburi R, Coates A, et al. Standardisation of spirometry. Eur Respir J 2005;26(2):319338.

19. Pereira CA, Sato T, Rodrigues SC. New reference values for forced spirometry in white adults in Brazil. J Bras Pneumol 2007;33(4): 397-406.

20. Celli BR, Cote CG, Marin JM, Casanova C, Montes de Oca M, Mendez RA, et al. The body-mass index, airflow obstruction, dyspnea, and exercise capacity index in chronic obstructive pulmonary disease. N Engl J Med 2004;350(10):1005-1012.

21. da Silva RA, Bilodeau M, Parreira RB, Teixeira DC, Amorim CF. Age-related differences in time-limit performance and force platform-based balance measures during one-leg stance. J Electromyogr Kinesiol 2013;23(3):634-639.

22. Piirtola M, Era P. Force platform measurements as predictors of falls among older people: a review. Gerontology 2006;52(1):1-16.

23. Michikawa T, Nishiwaki Y, Takebayashi T, Toyama Y. One-leg standing test for elderly populations. J Orthop Sci 2009;14(5):675685

24. Podsiadlo D, Richardson S. The timed "Up \& Go": a test of basic functional mobility for frail elderly persons. J Am Geriatr Soc 1991; 39(2):142-148.

25. Shumway-Cook A, Brauer S, Woollacott M. Predicting the probability for falls in community-dwelling older adults using the Timed Up \& Go test. Phys Ther 2000;80(9):896-903. 


\section{Static and Functional Balance in Individuals With COPD}

26. Mesquita R, Janssen DJ, Wouters EF, Schols JM, Pitta F, Spruit MA. Within-day test-retest reliability of the Timed Up \& Go test in patients with advanced chronic organ failure. Arch Phys Med Rehabil 2013;94(11):2131-2138.

27. ATS Committee on Proficiency Standards for Clinical Pulmonary Function Laboratories. ATS statement: guidelines for the six-minute walk test. Am J Respir Crit Care Med 2002;166(1):111-117.

28. Holland AE, Spruit MA, Troosters T, Puhan MA, Pepin V, Saey D, et al. An official European Respiratory Society/American Thoracic Society technical standard: field walking tests in chronic respiratory disease. Eur Respir J 2014;44(6):1428-1446.

29. Britto RR, Probst VS, de Andrade AF, Samora GAR, Hernandes NA, Marinho PEM, et al. Reference equations for the six-minute walk distance based on a Brazilian multicenter study. Braz J Phys Ther 2013;17(6):556-563.

30. Troosters T, Probst VS, Crul T, Pitta F, Gayan-Ramirez G, Decramer M, Gosselink R. Resistance training prevents deterioration in quadriceps muscle function during acute exacerbations of chronic obstructive pulmonary disease. Am J Respir Crit Care Med 2010; 181(10):1072-1077.

31. Robles PG, Mathur S, Janaudis-Fereira T, Dolmage TE, Goldstein RS, Brooks D. Measurement of peripheral muscle strength in individuals with chronic obstructive pulmonary disease: a systematic review. J Cardiopulm Rehabil Prev 2011;31(1):11-24.
32. Neder JA, Nery LE, Shinzato GT, Andrade MS, Peres C, Silva AC. Reference values for concentric knee isokinetic strength and power in nonathletic men and women from 20 to 80 years old. J Orthop Sports Phys Ther 1999;29(2):116-126.

33. Porto EF, Castro AA, Schmidt VG, Rabelo HM, Kümpel C, Nascimento OA, Jardim JR. Postural control in chronic obstructive pulmonary disease: a systematic review. Int J Chron Obstruct Pulmon Dis 2015;10:1233-1239.

34. Boer MC, Fernandes KB, Oliveira MR, Pires-Oliveira DA, Marquez AS, Teixeiras DC, DaSilva RA. Postural control during one-legged stance is compromised in elderly adults with osteoporosis and osteopenia. Eur J Phys Rehabil Med 2015;51(5):663-665.

35. Cooper R, Hardy R, Aihie Sayer A, Ben-Shlomo Y, Birnie K, Cooper $\mathrm{C}$, et al. Age and gender differences in physical capability levels from mid-life onwards: the harmonisation and meta-analysis of data from eight UK cohort studies. PLoS ONE 2011;6(11):e27899.

36. Johnson ST, Kipp K, Hoffman MA. Spinal motor control differences between the sexes. Eur J Appl Physiol 2012;112(11):3859-3864.

37. Nolan L, Grigorenko A, Thorstensson A. Balance control: sex and age differences in 9- to 16-year-olds. Dev Med Child Neurol 2005; 47(7):449-454

38. Teixeira DC, Hernandes NA, Probst VS, Ramos EMC, Brunetto AF, Pitta F. Profile of physical activity in daily life in physically independent elderly men and women. Rev Bras Educ Fís Esporte 2012; 26(4):645-655. doi: 10.1590/\$1807-55092012000400009 